\title{
Metodologia feminista e direitos reprodutivos no Centro de Saúde Santa Rosa, Niterói (RJ)
}

Feminist methodology and reproductive rights in the Santa Rosa Health Center, Niterói (RJ)

Elaine França da Silva'

RESUMO O presente trabalho tem por objetivo examinar práticas feministas e femininas, em especial, aquelas presentes em uma pedagogia voltada para o processo de empoderamento político das mulheres, a Linha da Vida, largamente utilizada nas lutas dos anos de 1980 por direitos reprodutivos e, mais especificamente, pela instituição do Programa de Assistência Integral à Saúde da Mulher. Essa pedagogia, propagada no Brasil, marca a segunda onda feminista, estimulando o protagonismo das mulheres, favorecendo a tomada de consciência e definindo orientações de lutas pelas transformações desejadas. Para tanto, este trabalho apresenta um estudo tomado da experiência do Centro de Saúde Santa Rosa, em Niterói (RJ), a partir de 1984.

PALAVRAS-CHAVE Mulheres; Assistência integral à saúde; Feminismo.

ABSTRACT The present work aims to examine feminist and feminine practices, special, those present in a education focusing on the process of political empowerment of women, the Life Line, widely used in the fighting of the eighty's for reproductive rights and, more specifically, for the institution of the Integral Assistance Program to Women's Health. This practice, propagated in Brazil, sets the second feminist wave, stimulating the feminine prominence, fostering the awareness and stablishing fighting orientations for the desired changes. Therefore, this work presents a study based on the Santa Rosa Health Center, in Niterói (RJ), since 1984.

KEYWORDS Women; Comprehensive health care; Feminism. 


\section{Introdução}

Nos anos 1980, presenças femininas e feministas na construção do Programa de Assistência Integral à Saúde da Mulher (PAISM) marcaram o árduo caminho percorrido pelas mulheres rumo ao seu reconhecimento político, ao longo de sucessivas décadas. Elas sugeriram processos de empoderamento e novos protagonismos políticos, todos de suma importância para a construção das políticas sociais no Brasil. Através de experiências de troca entre mulheres desiguais, tensões políticas se avolumaram, impulsionando a redefinição dos rumos das políticas de saúde para as mulheres no Brasil.

Experimentando um importante acúmulo de saberes, elas construíram um programa afinado com seus anseios de liberdade reprodutiva, tornando o PAISM um lugar comum delas próprias. Nesse momento, uma nova pedagogia feminista, vinda de fora do País, as auxiliou, pavimentando novas vias rumo ao empoderamento e ao conhecimento de suas identidades.

A pedagogia - em especial, a Linha da Vida - estimulou a superação do Programa Materno-Infantil e a implantação do PAISM, com base na perspectiva das mulheres como sujeitos (COSTA, 2007A).

A prática pioneira realizada no Centro de Saúde Santa Rosa, no município de Niterói (RJ), iniciada em 1984 - hoje, Policlínica Regional Dr. Sérgio Arouca - oferece o interessante estudo de caso do tempo enunciado aqui. Esse espaço fala de lutas pela saúde reprodutiva, fala de protagonismos femininos e feministas e, em especial, de um masculino.

Este artigo, de caráter reflexivo, faz o resgate de uma experiência pedagógica de vital importância histórica e política para a atenção à saúde das mulheres pela perspectiva crítica de gênero, da integralidade e das pedagogias reflexivas, iniciadas nos movimentos sociais de mulheres. $\mathrm{O}$ artigo tem por fontes registros documentais dessas experiências políticas ocorridas no município de Niterói (RJ), em particular, as efetivadas no Centro de Saúde Santa Rosa.

\section{Quando tensões definem rumos para políticas de saúde}

Com anos de experiência em questões relativas à Saúde da Mulher, a unidade de saúde, possuía um espaço privilegiado, que reunia profissionais interessados em mudar o estado da saúde no município. Inaugurada em 1953, localizava-se no chamado 'velho casarão', no bairro de Santa Rosa. Duas décadas depois, no ano de 1974, a unidade de saúde transferiu-se para sua sede própria, na Rua Ary Parreiras, no bairro Vital Brazil, Niterói (RJ). Espaço muito utilizado para a capacitação de profissionais, era um pólo de treinamento do Ministério da Saúde. Médicos, enfermeiros, assistentes sociais e psicólogos eram remanejados de diferentes áreas da gestão pública, objetivando a organização de equipes de excelência para integrarem o espaço da saúde reprodutiva. Naquela conjuntura, houve uma permissão governamental para que profissionais do Instituto Nacional de Assistência Médica da Previdência Social (Inamps) exercessem atividades nas redes básicas de saúde, nas regiões periféricas da cidade. Essa experiência foi o resultado de uma mobilização maior de diversas instituições e movimentos sociais, com destaque para os movimentos sociais de mulheres.

$\mathrm{Na}$ esteira das transformações políticas que ocorreram nas consciências femininas e feministas no ocidente, a 'segunda onda do feminismo' retomou força no Brasil nos anos de 1970, e como resultado de profundas transformações da vida em comum, também foi responsável pelo afloramento das lutas por direitos reprodutivos. Tratando-se destes tempos, o movimento feminista já possuía influência entre intelectuais 
brasileiras. Ideias feministas -especialmente, o feminismo europeu - foram introduzidas no País, dando substância ao início do movimento de mulheres contemporâneo (COSTA, 2004). Naquele tempo, mulheres engajadas politicamente acabaram por envolver-se em questões para além das suas próprias, engrossando as lutas pelo fim da repressão militar. Estes novos protagonistas do cenário político brasileiro se associaram a outras militantes de esquerda, que retornaram ao País, após a Lei de Anistia ser aprovada, em 1979. Movimentações advindas de 'lutas gerais e lutas específicas' deram indícios das dicotomias existentes no interior dos movimentos (PEDRO, 2006).

Reunidos em torno de novas demandas, os movimentos sociais de mulheres evidenciaram a pluralidade das suas reivindicações em tempos de ditadura. Naquele período, muitos movimentos passaram a reivindicar a criação de direitos antes negligenciados pelo Estado, como, por exemplo, os direitos sociais, culturais e de gênero. Especialmente no Brasil, os feminismos tomaram um novo impulso, afirmando que o 'pessoal era político'. Surgiram, por esses anos, as primeiras falas sobre direitos sexuais e reprodutivos, que, segundo Ávila (2003), dizem respeito à igualdade e à liberdade pessoais nas decisões relativas a essas esferas, e o reconhecimento da sexualidade e da reprodução como dimensões da cidadania. Nos anos seguintes, muitos foram os marcos que legalizaram esses direitos.

Os feminismos no Brasil se caracterizaram por sua forma peculiar de organização, estruturados em bases locais; trocaram experiências com moradores das periferias (SARTI, 2001). Em Niterói (RJ), mesmo que na invisibilidade, na maioria das vezes, houve registros de que as mulheres se envolveram em lutas pela garantia de direitos básicos de sobrevivência, pela redemocratização do País.

Naquele período, ideologias feministas seguiram disputando espaços com a Igreja
Católica. Questões como sexualidade, aborto e planejamento familiar, entre outros assuntos tidos como do âmbito privado, começaram a ser debatidos com mais fervor entre um maior número de mulheres. A mobilização política da época permitiu a criação de 'grupos de reflexão', inicialmente nos estados do Rio de Janeiro e de São Paulo (SARTI, 2001). Sem ressonância pública e sem interferência masculina, até aquele momento, esses grupos eram formados por mulheres conhecidas, amigas (PEDRO, 2006).

Duas foram as vertentes feministas que influenciaram a formação desses grupos: uma vinda da França e outra, dos Estados Unidos. No que diz respeito à vertente europeia, verifica-se sua contribuição teórica acentuada, voltada às discussões sobre a circulação de mulheres no âmbito público/privado e seus rebatimentos históricos: a servidão doméstica e a 'dupla jornada de trabalho'. Naquele período, os coletivos franceses já atuavam denunciando tais desigualdades, repensando o caráter político da 'divisão sexual do trabalho', tensões que modificariam as relações sociais (HIRATA; KERGOAT, 2007). Em contrapartida, a vertente americana teve como característica predominante a prática de 'grupos de reflexão' voltados para a transformação pessoal e cultural (PEDRO, 2006).

No Brasil, um dos primeiros grupos surgiu no estado de São Paulo, no ano de 1972, e logo depois no estado do Rio de Janeiro, por conta de Branca Moreira Alves. Em sua passagem pelos Estados Unidos, Branca entrou em contato com esses grupos de reflexão e, ao voltar ao Brasil, os formou. Inicialmente, ela uniu mulheres de diferentes idades em um só grupo, mas, a diferença de geração as inibiu. Então, optou por dividir o grupo entre as da geração de sua mãe e as de sua própria geração. O grupo das mais jovens durou até meados da década de 1970 (PEDRO, 2006).

A fertilidade desses grupos desnudou um complexo processo de formação de identidades coletivas, presentes nas iniciativas dos coletivos SOS Corpo, no estado do Rio 
de Janeiro e no Recife (PE) (COSTA, 2002), e na militância do grupo Ceres. Formado por Branca Moreira Alves e Jacqueline Pitanguy, entre outras feministas, este último era pioneiro na formação dos 'grupos de reflexão', contando, inclusive, com a confecção de um livro: 'O espelho de Vênus' (COSTA, 2007B), publicação coletiva que trouxe contribuições importantes para o reconhecimento das experiências corporais e da subjetividade feminina no Brasil.

Tais experiências se multiplicaram, contudo, o caminho trilhado pelo trânsito dessas práticas falava de conflitos e do surgimento de redes de solidariedade.

Nessa perspectiva, Pedro (2006) indica que militantes de esquerda, tidas como mais radicais, não se identificaram com os 'grupos de reflexão'. Segundo elas, as lutas por autonomia e controle do corpo seriam consideradas 'ideias específicas' e, portanto, divisionistas da 'luta geral', pelo fim da ditadura, que consideravam prioritária.

$O$ fato de os grupos terem surgido nas rodas feministas de classe média também foi motivo para que muitos militantes apelidassem os círculos de 'chá das cinco das ricas ociosas' (PEDRO, 2006).

Mas a resistência ao preconceito se fortaleceu e, posteriormente, os 'grupos de reflexão' se espalharam, ganhando sucessivas sistematizações como práticas educativas na área da saúde e em outras áreas. Na década de 1980, deles se utilizaram programas de capacitação de recursos humanos do Ministério da Saúde, programas de saúde da mulher das secretarias de estados e municípios, congressos internacionais de saúde, grupos autônomos de mulheres e grupos internacionais idealizadores de ações em favelas, entre outros movimentos sociais e instituições no País (COSTA, 2009). Como saldo desses anos, essas práticas permitiram pequenas revoluções individuais e coletivas possibilitando o empoderamento político daquelas mulheres.

Protagonismos femininos, não necessariamente feministas, também estavam intimamente associados à sexualidade e a luta por direitos reprodutivos:

Questões relativas à vivência de uma sexualidade plena e livre de riscos, o controle do próprio corpo e o direito de decidir sobre como e quando ter filhos constituíram-se como temas centrais de reflexão e de vivências. (FERREIRA; MARQUES, 2008, P. 1).

O avanço se fez, notadamente, com a conquista de direitos em um campo de muitas interdições: o da sexualidade e da reprodução.

Isso se moveu ainda na revisão dos programas vinculados à proteção materna. Alguns profissionais elevaram a voz nesse período, defendendo o direito à saúde em sua integralidade. Temas como prazer sexual sem gravidez, uso de contraceptivos e esterilização entraram para o elenco das questões que começaram a mobilizar mulheres comuns em torno dos direitos reprodutivos (COSTA, 2009). Obviamente, essa transformação da consciência feminina sobre a sexualidade e a vida reprodutiva não surgiu de forma isolada, ela necessariamente incluiu, também, decisões do sexo masculino. A tentativa de repensar o papel da mulher e a atenção que ela estava recebendo, até então, por parte das políticas públicas de saúde vieram acompanhadas de uma série de transformações políticas e ideológicas da vida em comum e da intimidade. Desde meados da década de 1970, o campo da saúde torna-se espaço de intervenções políticas de movimentos sociais de mulheres, com ações dirigidas tanto ao exercício dos direitos sexuais e reprodutivos quanto à qualidade da atenção nos serviços de saúde (FERREIRA; MARQUES, 2008).

\section{Espaços de sociabilidade e tomada de consciência: experiências que compõem o PAISM}

O Centro de Saúde foi pioneiro na realização das oficinas de 'reflexão e ação' (ou dos 'grupos de reflexão'), posteriormente 
conhecidas como Linha da Vida, por conta de Martha Zanetti. Disseminada em vários países do mundo, recebeu nomes como Herstories ou Bitch sessions (COSTA, 2009). A pedagogia feminista facilitou o trabalho da integralidade no campo da saúde. Ela se organizou por iniciativa de algumas feministas que as teriam vivido no exterior. Algumas promoveram, nos estados do Rio de Janeiro e também de São Paulo, reuniões de mulheres próximas e em diferentes casas. Essas experiências foram deslocadas, por algumas profissionais de saúde, para seus ambientes de trabalho. Forjou-se, assim, uma pedagogia experimental de reflexão e ação, de natureza informal, ao alcance de apenas mulheres próximas, conhecidas, mas que se multiplicou, em sucessivas formalizações por profissionais da área de saúde. Desvendou-se um processo contínuo de politização.

É interessante relacionar a importância desses grupos no desenvolvimento do PAISM. Esses espaços foram de extrema importância para que mulheres, homens e profissionais da saúde pudessem pensar que tipo de política gostariam de construir. Os grupos de reflexão se propagaram nas unidades de atenção primária no estado do Rio de Janeiro, houve uma intensa capacitação de profissionais, inclusive, com o treinamento de Agentes Comunitários de Saúde (COSTA, 2007A).

Buscando promover a afirmação da mulher como sujeito de direitos com vistas ao reconhecimento de sua cidadania, as práticas educativas inovadoras foram criadas através das experiências dos movimentos de mulheres em seus diversos momentos. Algumas variações puderam ser verificadas na metodologia de desenvolvimento dessas oficinas, embora, na maioria das vezes, elas seguissem uma mesma sistematização. Eram propostas etapas de produção coletiva, em que as mulheres reunidas, em sequência, falavam de suas existências, segundo etapas de vida: do nascimento, da infância, da adolescência, da juventude, da maturidade, da velhice ou da expectativa de envelhecimento. Em tais etapas, recordavam acontecimentos marcantes de suas vidas; em seguida, eram contadas as experiências enquanto uma coordenadora registrava as falas em um grande papel colocado no chão. Com a sucessão de registros, de memórias vividas, eram realizadas reflexões sobre as semelhanças e diferenças entre as experiências. E, dentro desse universo de subjetividades, ocorriam as trocas de saberes, momentos de interação entre mulheres totalmente diferentes, que se viam nas experiências de outras mulheres, em um contínuo processo de empoderamento, que perpassava traumas, dores, prazeres, preconceitos. Em outra etapa, elas definiam, em grupos, rumos para as lutas relativas às questões de direito reprodutivo, estabelecendo metas a serem alcançadas e responsabilidades pessoais, visando demarcar pautas para o PAISM a serem conduzidas pela unidade de saúde.

No Brasil, as oficinas se multiplicaram, alcançando vários estados, desde meados dos anos 1970. Em Niterói, município do Rio de Janeiro, essa metodologia levou mulheres a darem depoimentos sobre suas vidas e a se engajarem em lutas sucessivas no âmbito da saúde reprodutiva. No Centro de Saúde, a introdução dessa pedagogia feminista foi feita pela Prof ${ }^{a}$. Suely Gomes Costa, da Escola de Serviço Social da Universidade Federal Fluminense (UFF), em 1984 e nos anos seguintes, na condição de orientadora de estágio discente da unidade. Ela viveu a experiência da Linha da Vida, em um evento promovido pela Comissão dos Direitos Reprodutivos, criada na Assembleia Legislativa do Estado do Rio de Janeiro, por Lucia Arruda, deputada estadual e militante feminista (PT). Isso se deu por um convite ocasional feito a ela pela Prof ${ }^{a}$. Hildete Pereira de Mello, da Faculdade de Economia (UFF), militante feminista, quando de uma ida ao Centro de Saúde para uma palestra. Vivida a experiência, a Prof ${ }^{a}$. Suely a introduziu entre profissionais do Centro de Saúde, buscando obter estímulos à implementação do PAISM, sob o 
governo Brizola, nos termos definidos pela Comissão Legislativa (COSTA, 2007A). A Linha da Vida, como pedagogia emancipatória, foi empregada e propagada por alunos e profissionais do Centro de Saúde, e engendrou um efeito multiplicador de muitas iniciativas, tendo sido totalmente abraçada por César Macedo, diretor da unidade à época.

O profissional responsável por buscar novos rumos para a saúde do município de Niterói (RJ), em especial, no período em que esteve à frente do Centro de Saúde Santa Rosa, na década de 1980, possibilitou que uma série de atividades de cunho feminista ocorresse na unidade. Médico sanitarista, Dr. César Roberto Braga Macedo objetivou a desconstrução de toda e qualquer forma institucionalizada e 'engessada' de fazer saúde. Além de colaborar para o desenvolvimento de novas práticas reflexivas entre usuários e profissionais da área, foi um dos primeiros homens, na unidade, a estar em um ambiente ocupado por mulheres, estimulando iniciativas e sucessivos eventos com o uso da Linha da Vida. Também a seu convite, Martha Zanetti, a organizadora de um texto de sistematização da Linha da Vida ao Centro de Saúde, fez um debate sobre essa metodologia para um auditório lotado por quadros dessa unidade e de outras, tornando públicas as orientações em marcha. César Macedo se apropriou de tal pedagogia, reconhecendo-a como um importante instrumento de sensibilização para mudanças de práticas médicas e divulgando-a entre os mais diversos sujeitos.

A pesquisadora Suely Gomes Costa defendia a importância de valorizar a experiência ocorrida no Centro de Saúde através dos olhos do médico, em especial. Segundo ela, o nome de César Macedo deve ser lembrado como de extrema relevância na condução das ações ali desencadeadas (COSTA, 2010).

Suely Gomes Costa informa:

Compúnhamos uma equipe que, então introduzia, nessa unidade, inovações cruciais nas regras de atendimento em geral e no nascente PAISM, depois espraiadas para outras unidades de saúde do município e do Estado. (COSTA, 2010, P. 2).

Naquele instante, novos atores somaram forças, fazendo circular, tanto no ambiente acadêmico quanto no das práticas cotidianas de saúde, novas perspectivas para a tomada de consciência política, de autoconhecimento e de ações focadas em demandas sociais reconhecíveis. Com o encontro de muitos mundos, até então, distintos, as questões postas no dia-a-dia dos profissionais e usuários eram percebidas como questões que também estavam presentes nos debates e nas pautas de luta travadas pelos movimentos de mulheres.

Lembro-me [...] de muitas tensões vividas por mulheres, profissionais de saúde que, ao contrário desse médico, negaram-se a participar, por exemplo, de dinâmicas de grupo [...] centradas na linha da vida de cada um. (COSTA, 2010, P. 3).

Ainda segundo Suely Gomes Costa, muitos profissionais se negariam a participar das oficinas, alegando não terem sido treinados a falar de si, apenas a ouvir e falar do outro.

Mesmo assim, a pedagogia foi capaz de formar grandes grupos de reflexão em torno de assuntos que outrora eram mantidos em segredo pelas mulheres, como ainda é o caso do aborto. Tivemos ainda, discussões que, infelizmente, pouco avançaram em matéria de ações concretas, como também é o caso da cultura da reprodução enquanto 'assunto de mulher', o que reiteradamente colabora para o afastamento dos homens das responsabilidades reprodutivas. "A ausência masculina nos assuntos da reprodução e o quanto isso é familiar aos profissionais de saúde, nos reporta a noção de estranhamento nos assuntos da reprodução" (SANTOS, 2006, P. 33). Isso tem se movido lentamente ao longo das décadas, mas o 
quanto dessa cultura persiste? Os atuais Programas de Planejamento Familiar têm se caracterizado como 'espaço de mulheres' e comprovado a quase inevitável feminilização do PAISM.

Não há como contestar que todas essas experiências ocasionariam redefinições no limite do privado e do público; elas acabaram por moldar novas relações sociais, inclusive e principalmente, no interior das famílias. Ao perceberem-se sujeitos de uma 'opressão' específica, as mulheres passaram a refletir sobre seus papéis sociais, verificando que um enorme volume de trabalho era realizado gratuitamente por elas, trabalho socialmente desvalorizado, invisibilizado cotidianamente (HIRATA; KERGOAT, 2007). Logo, o trabalho doméstico e, com ele, o papel materno, passaram a ser questionados.

Para uma mudança dessa magnitude, admite-se, teria ocorrido um importante acúmulo de saberes e de experiências. Ele se expressou, com maior nitidez, nos anos 1980, quando, então, buscou-se evidenciar e debater a forma pela qual as mulheres vivenciavam, no isolamento de seus lares, muitas das suas questões existenciais. Sobretudo, muitas vezes, sofrendo distintas formas de violência de gênero, violência doméstica, intrafamiliar.

Heleieth Saffioti (2002), pioneira na análise da condição da mulher sob uma perspectiva de classes, me faz atentar para a complexidade dessas relações violentas entre homens e mulheres, relações envoltas em uma realidade multifacetada, ideologicamente sustentada. Percebo, ainda, que mulheres também oprimem e, no âmbito das relações privadas, aceitam o papel de 'rainhas-do-lar' porque ganham compensações com a fragilidade, como também resistem e transgridem (COSTA, 2004).

Segundo Andrade (2014), a

história da mulher sempre vítima e jamais motor de qualquer opressão trata as mulheres todas como se fossem seres sem vontade, sem legitimidade, que nada sabem sobre a sociedade e as violências, sempre fracas demais, sem agência.

Mulheres são sempre vítimas? Terrenos pouco explorados indicam relações entre mulheres desiguais. Logo, atento para a complexidade dos sistemas de poder e subordinação que perpassam relações de classes, étnicas e geracionais, entre tantas outras, em suas muitas interseções. No que diz respeito às desigualdades entre as mulheres, isso é patente (COSTA, 2004).

Em princípio, a romantização construída em torno da igualdade, conceito em que as mulheres se percebem como 'irmãs', ofuscava as tensões nas relações, que estavam longe de serem equacionadas. A Linha da Vida, muito embora tenha sido uma pedagogia inovadora para a época, reunia as mulheres ao redor dessa suposição de irmandade, reafirmando características biológicas (COSTA, 2009). Ao defender que mulheres são iguais porque menstruam, porque engravidam, a Linha da Vida acabava por invisibilizar problemas que perpassavam os debates de gênero, como a pouca participação de usuários homens nas oficinas e as homossexualidades.

Ainda assim, essas experiências pedagógicas foram um importante passo, resultado de movimentações públicas das mulheres, momento em que produziram cultura, através de peças, jornais, revistas e congressos. Aqueles foram tempos de organização de diversos grupos autônomos de mulheres em torno de questões específicas. Um exemplo e 'produto' dessa movimentação política foi a construção do PAISM, no início da década de 1980, tempos de 'rebeldia' e contestação.

Assim, em 1983, surge o PAISM, em resposta à Comissão Parlamentar de Inquérito sobre problemas populacionais, a pedido do Presidente João Baptista de Oliveira Figueiredo (COSTA, 2004). Naqueles anos, as questões sobre o crescimento populacional já afloravam no mundo, e o tema 
'planejamento familiar' mostrava-se recorrente nas conferências sobre população, em 1974, em Bucareste; em 1984, no México; e em 1994, no Cairo.

Os movimentos sociais, militantes dessa área, avaliaram os resultados da Conferência do Cairo como um grande avanço no que diz respeito à formalização do conceito de saúde reprodutiva. Nessa perspectiva, o direito das pessoas decidirem se querem ou não ter filhos e o direito à livre reprodução sem discriminação, por exemplo, passaram a ser garantidos e defendidos (BRASIL, 2010). Em relação à saúde reprodutiva, a Conferência Internacional sobre População e Desenvolvimento (CIPD) ratificou o conceito definido em 1988 pela Organização Mundial da Saúde (OMS).

A saúde reprodutiva, se bem posso definir, é parte de um movimento mais amplo da saúde, que traduz um estado de luta e rebeldia não necessariamente advindo de feministas, mas de atores sociais comprometidos - incluindo protagonismos masculinos - em mudar o estado das coisas.

A pedagogia Linha da Vida orienta a superação do Programa Materno-Infantil e a implantação do PAISM com base na perspectiva das mulheres como sujeitos, sistematizando a noção de integralidade (COSTA, 2007A). Mas, de fato, com que tipo de cultura o PAISM tentaria romper? Quais teriam sido as expectativas sobre o programa?

Ao observar as árduas movimentações políticas femininas e feministas em defesa dos direitos reprodutivos, me detenho à complexa relação entre ciência, cultura e medicina que moldaria as primeiras políticas de saúde para mulheres.

Antes, na década de 1920, a preocupação com a higiene de ambientes e com o perigo de doenças relacionadas a bactérias e insetos era grande. Ações de saúde e prevenção estavam diretamente ligadas a práticas femininas. A preocupação demográfica e o medo do alastramento de doenças venéreas provocariam a intensificação de processos educativos voltados para a formação de mães mental e fisicamente 'saudáveis' (FREIRE, 2006).

Ainda segundo Freire (2006), o estabelecimento da maternidade científica nas primeiras décadas do século XX, no Brasil, instituiu decisiva influência sobre a construção das políticas relativas à saúde da mulher. Considerada como o exercício da maternidade embasada nos saberes academicamente legitimados, a maternidade científica foi objeto de práticas educativas próprias e de supervisão médica. Essa ideologia direcionou todas as demais políticas de saúde desenvolvidas para a mulher, evidenciando o poder normatizador de instituições médicas e do Estado. Nas décadas de 1930 a 1970, os programas materno-infantis traduziram o espírito da 'nova mulher-mãe', baseado em sua especificidade biológica.

Se as ações do Estado em relação a questões de saúde estavam intimamente ligadas ao ambiente familiar e ao papel de cuidadora exercido pela mulher, por outro lado, a extensão da prole definia a intensidade dos encargos diários, regulando o tempo doméstico. Foram (e ainda são) muitos os impedimentos aos deslocamentos das mulheres para a esfera pública, ressalvados alguns clássicos exemplos de exercício de poder de 'mulheres notáveis'. Mudanças de regulação do tempo feminino levaram a constantes negociações e rearranjos das relações de gênero, atualizações de tantas desigualdades (COSTA, 2002).

Não há como tratar das movimentações políticas femininas e feministas nos espaços públicos sem considerar os sistemas de proteção social primários, estratégias informais utilizadas para compensar as precárias redes de proteção estatal. São essas relações cotidianas do cuidar que atualizam desigualdades seculares entre mulheres no que concerne ao acesso a direitos sociais (COSTA, 2002). Constata-se que, tanto a questão reprodutiva quanto os cuidados com os filhos continuam sob responsabilidade das mulheres. Ainda que alguns avanços tenham sido 
verificados, no que concerne à divisão de tarefas domésticas com homens, as responsabilidades referentes à saúde reprodutiva permaneceram como 'assunto de mulher'. Não obstante, ao longo de sucessivas décadas, homens e mulheres buscam o controle da prole, mesmo que de forma clandestina (SANTOS, 2006).

No campo da saúde, evidenciam-se mudanças nas relações sociais. Ao longo do tempo, novas tendências comportamentais surgiram. Alguns intelectuais também refletem sobre o modelo hegemônico de atendimento médico, de tantos silêncios sobre a sexualidade e as questões do corpo, indicando que, desde aquela época, as brasileiras vêm rompendo com o clássico papel social que lhes é atribuído pela maternidade. $\mathrm{O}$ controle da fecundidade passa a ser aspiração das mulheres, que colocam em debate novos padrões de comportamento sexual, desvinculados da maternidade. Essa conjuntura favorece discussões sobre a criação de novas políticas de saúde (COSTA, 2004).

Diversas correntes de saber e práticas sociais tiveram influência na formulação do PAISM: desde atores que defendiam a proposta da reforma sanitária até os movimentos de mulheres e feministas - estes últimos marcaram participação através das propostas educativas. O programa inovou ao tentar abordar questões como as relações de poder no interior dos serviços de saúde e ao estimular a inserção dos movimentos sociais, representando os interesses dos sujeitos envolvidos (COSTA, 2004).

O PAISM surgiu apresentando em seus pressupostos a ideia de que a saúde não se restringe à mera oferta de assistência médica, mas abrange a execução de outras políticas sociais, que ampliam a qualidade de vida dos sujeitos. Nesse contexto, uma abordagem diferenciada da saúde da mulher foi defendida baseada no conceito de atenção integral à saúde das mulheres. Esse 'novo espírito' marcou a tentativa de ruptura com a visão tradicional acerca das necessidades da população feminina, sobretudo no âmbito das práticas médicas centradas nas mulheres como reprodutoras. O PAISM inovou ao propor a implantação do programa de planejamento familiar em nível nacional, rompendo com a lógica que, até então, nortearia as intervenções sobre os corpos das mulheres (COSTA, 2004).

Na década de 1980, o movimento pela saúde já acumulava experiências, debatendo o controle populacional e o descontrolado uso de métodos contraceptivos, principalmente o procedimento de esterilização. No processo de questionamento, as mulheres também debateram o exercício da medicina e da ginecologia, em particular.

Todavia, constatados avanços no âmbito dos direitos reprodutivos, os feminismos perderam muito de sua força de persuasão diante dos precários serviços públicos de saúde (COSTA, 2002). Os planos privados de saúde tornaram-se saídas comumente utilizadas por mulheres interessadas no procedimento de esterilização, tentativas de impedir o crescimento da prole e de garantir a participação no mercado de trabalho.

Vejo que parte dos insucessos verificados na implementação do PAISM - que não se restringem a essa experiência localizada que narro, mas se estendem a outros casos compartilhados - estão associados à complexa articulação de interesses políticos antagônicos que marcam a gênese do programa. Como bem examina Giffin (2002, P. 109):

Tanto a situação de saúde reprodutiva das mulheres brasileiras como a condição orçamentária do PAISM indicam, atualmente, os reais limites da luta política restrita ao setor saúde, seja no plano nacional ou no palco dos discursos internacionais,

fortemente influenciados pelas políticas populacionais focais de cunho controlista.

Tendo em vista os impasses, equívocos e frustrações diante da não concretização do PAISM 'idealizado', muitos coletivos foram 
capazes de repensar suas formas de atuação. Mary Garcia Castro (2001) defende que os feminismos puderam, a partir das novas conjunturas, reorganizar-se de forma a repensarem paradigmas e a reconceituarem práticas políticas. Muitas militantes, que nos anos de 1970/1980 participaram dos movimentos sociais de mulheres, inserem-se hoje em outras frentes de luta, não necessariamente em organizações de base comunitária. Elas ocupam meios de comunicação, fundaram e fundam ONGs, integram partidos políticos, fazem carreiras na academia ou em outras áreas profissionais.

No final dos anos 1980, as lutas por direitos reprodutivos e por políticas sociais avançaram, mesmo sob sérias divergências entre feministas e não feministas com relação à descriminalização do aborto e do atendimento às demandas por laqueadura de trompas (COSTA, 2002). Os frutos gerados pela experiência localizada no Centro de Saúde Santa Rosa foram uma tentativa audaciosa de reverter o estado da saúde reprodutiva, desconstruindo a cultura de que reprodução é 'assunto de mulher'. As práticas possibilitaram a produção de conhecimento a respeito do próprio planejamento familiar e seu papel. A pedagogia atingiu usuários e profissionais de saúde de várias localidades de Niterói (RJ), incluindo os bairros de Ititioca e Viradouro. Além disso, alcançou militantes do Partido dos Trabalhadores (PT), do Partido Democrático Trabalhista (PDT) e do Partido do Movimento Democrático Brasileiro (PMDB) (COSTA, 2009).

\section{Referências}

\begin{abstract}
ANDRADE, D. Mulheres são sempre vítimas? Géledes: Instituto da Mulher Negra. Disponível em: <http:// www.geledes.org.br/mulheres-sao-sempre-vitimas/>. Acesso em: 14 jun. 2014.
\end{abstract}

ÁVILA, M. B. Direitos sexuais e reprodutivos: desafios para as políticas de saúde. Cadernos de Saúde Pública, Rio de Janeiro, v. 19, supl. 2, p. 465- 469, 2003.

BRASIL. Ministério da saúde. Saúde Sexual e Sáude Reprodutiva. Cadernos de Atenção Básica. Brasília, DF, 2010. Disponível em: <http://189.28.128.100/dab/docs/ publicacoes/cadernos_ab/abcad26.pdf >. Acesso em: 22 jul. 2014.

CASTRO, M. G. Gênero e poder. Leituras transculturais- quando o sertão é mar, mas o olhar estranha, encalha em recifes. Dossiê: Feminismo em questão, questões do feminismo. Cadernos Pagu, São Paulo, n. 16, p. 49-77, 2001.

COSTA, A. M. Atenção integral à saúde das mulheres: quo vadis? Uma Avaliação da Integralidade na Atenção à Saúde das Mulheres no Brasil. 2004. Tese (Doutorado em Ciências da Saúde) - Universidade de Brasília,
Brasília, DF, 2004.

COSTA, S. G. A voz das mulheres: linha da vida e associativismos feministas. Rio de Janeiro, anos de 1970-80. In: Cultura política e leitura do passado, Rio de Janeiro: Civilização Brasileira, 2007a, p. 438-455.

Culturas políticas e sensibilidades: pedagogias feministas, Rio de Janeiro, anos 1970-80. In: SOIHET, R. et al. Mitos, projetos e práticas políticas: memória e historiografia, Rio de Janeiro: Afiliada, 2009, p. 351-526.

Memória dividida das lutas por direitos reprodutivos: Niterói/Rio de Janeiro, anos 1970/1980. Fazendo Gênero 9: diásporas, diversidades, deslocamentos, p. 1-7, ago. 2010.

Movimentos feministas e feminismos. Estudos Feministas, Santa Catarina, v. 12, n. Especial, p. 22-36, set./dez. 2004

Proteção social, maternidade transferida e lutas pela saúde reprodutiva. Revista Estudos Feministas, Santa Catarina, v. 10, n. 2, p. 301-322, 2002. 
Silêncios, diálogos e os monólogos da vagina: instantes dos feminismos (Brasil, 1970-1990). Revista Esboços, Santa Catarina, v. 14, n. 17, p. 35-56, $2007 \mathrm{~b}$.

FERREIRA, S. L.; MARQUES, P. F. Saúde sexual e saúde reprodutiva - práticas de ONG feministas. Fazendo Gênero 8: Corpo, violência e poder. Santa Catarina, p. 1-6, ago. 2008.

FREIRE, M. M. L. Mulheres mães e médicos: discurso maternalista em revistas feministas (Rio de Janeiro e São Paulo, década de 1920). 2006. 336 f. Tese.

(Doutorado em História das Ciências e da Saúde) Fundação Oswaldo Cruz, Rio de Janeiro, 2006.

GIFFIN, K. Pobreza, desigualdade e equidade em saúde: considerações a partir de uma perspectiva de gênero transversal. Caderno Saúde Pública, Rio de Janeiro, v. 18, p. 103-112, 2002.

HIRATA, H.; KERGOAT, D. Novas configurações da divisão sexual do trabalho. Cadernos de Pesquisa. São Paulo, v. 37, n. 132, p. 595-609, set./dez. 2007.
PEDRO, J. M. Narrativas fundadoras do feminismo: poderes e conflitos (1970-1978). Revista Brasileira de História, São Paulo, n. 26, p. 249-272, dez. 2006.

SAFFIOTI, H. I. B. Contribuições feministas para o estudo da violência de gênero. Revista Labrys, Estudos

Feministas, Santa Catarina, n. 1-2, jul./dez. 2002.

SANTOS, A. E. L. Masculinidades e Saúde Reprodutiva: a experiência da vasectomia. 2006. Dissertação (Mestrado em Política Social) - Universidade Federal Fluminense, Niterói 2006.

SARTI, C. A. Feminismo e contexto: lições do caso brasileiro. Cadernos Pagu, São Paulo, n. 16, p. 31-48, 2001.

Recebido para publicação em janeiro de 2015

Versão final em março de 2015

Conflito de interesse: inexistente

Suporte financeiro: não houve 